\title{
Correction: The effect of day 1 postoperative gas fill on the outcome of vitrectomy for retinal detachment
}

Braden A. Young • Rachael C. Heath Jeffery • William K. Atkins • Rohan W. Essex (i)

Published online: 1 June 2020

(C) The Royal College of Ophthalmologists 2020

\section{Correction to: Eye}

https://doi.org/10.1038/s41433-020-0846-8

In the original article's XML, we stated co-author Dr Rachael C. Heath Jeffery's name incorrectly (we entered
"Heath" as part of her given name rather than her family name). We've corrected the XML (which automatically fixed the previously incorrect Pubmed indexing). 